\title{
El eclipse parcial de Plotino en la Edad Media y su recuperación en el Renacimiento*
}

\author{
Q Kevin Corrigan \\ Emory University, Estados Unidos
}

Recibido el 20/06/2019; aceptado el 23/08/2019.

\begin{abstract}
Resumen
Este artículo trabaja la presencia plotiniana en la Edad Media y el Renacimiento. En primer término, se presenta el movimiento de transmisión indirecta de las Enéadas a lo largo de la Edad Media y las ediciones que resurgen en el Renacimiento. En esta línea, se discute precisamente la presencia e influencia de las ideas plotinianas en pensadores medievales. En segundo término, se despliegan ciertas notas nucleares del pensamiento de Plotino -las tres hipóstasis y un solo universo- para luego, en tercer término, exponer las profundas coincidencias que pueden encontrarse en la estructura del pensamiento de Nicolás de Cusa -con el estudio del lenguaje de los binomios complicación-explicación, incontracto-contracto. Finalmente, se considera la posibilidad de incluir a ambos autores en una Gran Teoría Unificada que se despliega a lo largo de la Edad Media.
\end{abstract}

PALABRAS CLAVE: PLOTINO, NICOLÁS DE CUSA, ENÉADAS, HIPÓSTASIS, UNIVERSO.

The Partial Eclipse of Plotinus in the Middle Ages and his Recovery in the Renaissance

\begin{abstract}
This article studies the Plotinian presence in the Middle Ages and the Renaissance. First, it accounts for the indirect transmission of the Enneads throughout Medieval times and the editions that reappears in the Renaissance. In this regard, it discusses the presence and influence of Plotinian ideas on Medieval thinkers. Secondly, it examines some main points of Plotin's thought -the three hypostases and a single universe- and thirdly, presents the profound coincidences between Plotin and Nicholas of Cusa's ideas, analyzing the pairings enfolding-unfolding, uncontracted-contracted. Finally, it considers the possibility of reuniting both lines in a Grand Unified Theory that goes through all the Middle Ages.
\end{abstract}

KEYWORDS: PLOTIN, NICHOLAS OF CUSA, ENNEADS, HYPOSTASES, UNIVERSE.

* El siguiente texto es una traducción de Patristica et Mediævalia del original inglés publicado en este mismo volumen. 


\section{Introducción}

La historia de la erudición moderna sobre Plotino ha sido, en gran medida, la historia del establecimiento de un texto confiable y de llegar a comprender a Plotino en sus propios términos en el contexto del siglo III d.C. ${ }^{1}$ Pero el problema inmediato para cualquier lector moderno es que para llevar a cabo este proyecto hay que volver a los presocráticos, a Platón, a Aristóteles, al pensamiento helenístico y a los gnósticos, así como a las formaciones iniciales del pensamiento cristiano y, luego, a los desarrollos del pensamiento islámico y judío, para luego ir hacia adelante, al mundo medieval, donde la influencia directa de Plotino fue eclipsada o limitada, aunque indirectamente ubicua, y así, finalmente, hacia el Renacimiento y los mundos modernos. "Plotino" es, entonces, una peculiar fuerza de pensamiento y práctica que tiende a saltar las fronteras y a mantenerse fuera de los parámetros de la experiencia convencional.

El impulso más profundo del alma, dice Plotino, es hacia aquello que es más grande que ella (Enéada I.4 [46], 6: 17-18), ${ }^{2}$ y los mismos padres griegos, al igual que Agustín y Dionisio Areopagita, pudieron estar de acuerdo inmediatamente con este principio tan íntimo, aunque trascendente. Sin embargo, el "misticismo", y en particular el misticismo pagano, ${ }^{3}$ no pueden controlarse, especialmente si el impulso por lo que es superior a uno mismo no conduce a una institución secular o religiosa definida, sino a un Dios infinito, a un yo infinito e increado y, finalmente, a un cosmos infinito, como lo hizo en los casos de Meister Eckhart, Nicolás de Cusa y Giordano Bruno (sobre los principios plotinianos básicos de que el centro de todas las cosas está en todas partes y en ninguna -VI.4-5 [2425]-, y de que hay algo en nosotros que no ha descendido -IV.8 [6], 8)."Plotino" podría ser un aliado del cristianismo o el Islam contra las fuerzas del ateísmo o el materialismo reductivo, pero también podría ser un aliado para el establecimiento de una religión pagana alternativa, como en el caso de Thomas Taylor, o podría fácilmente ser estigmatizado por grupos cristianos después de la Reforma como una aberración oriental decadente-de la misma manera como, en tiempos más recientes, Harnack y Barth han enfatizado la fuerte división entre el buen sentido de la Biblia y los supuestos irracionalismos del helenismo, o como el estudio regulativo de la forma en Kant y los neo-kantianos borró radicalmente lo místico de las Formas de Platón a favor de las Formas como "conceptos-límite", "leyes" (Cohen) o "hipótesis" (Natorp) (Natorp, 2004: 9-43 y 453-483). "Plotino", sin embargo, no es cristiano o musulmán, sino un pagano; además, es completamente místico: las Formas no están sujetas a análisis conceptual; piensa fuera de los límites convencionales, especialmente en la medida en que uno de los paradigmas de pensamiento que estableció es que todo lo genuinamente inteligible es radicalmente holográfico, es decir, que en cada cosa todo está virtualmente contenido -especialmente Enéada V.8 [31], 4; tal pensamiento, por lo tanto, puede tener una resonancia radical con puntos de vista muy diferentes.

Por lo tanto, remonto el comienzo de la erudición moderna sobre Plotino a alguien que abrazó todas las características anteriores: el sacerdote florentino Marsilio Ficino, que parece haber entendido profundamente a Plotino en sus propios términos $\mathrm{y}$, al mismo tiempo, vio su pensamiento como una preparatio evangelica. Como dice Ficino,

\footnotetext{
1 Al preparar este trabajo, he usado principalmente Henry 1935; 1938; 1948; Schwyzer, 1951; O'Meara, 1992; Saffrey, 1996; Narbonne, Achard y Ferroni, 2012: ccli-ccxci.

2 La citación de las Enéadas es como sigue: I.4 indica el séptimo tratado (cifra arábiga 4) de la sexta Enéada (cifra romana I). Esto es seguido entre corchetes por el número cronológico, es decir, el orden en que Plotino escribió los tratados que conocemos gracias a la Vida de Plotino de Porfirio. Aquí I.4 es $46^{\circ}$ en el orden cronológico. Esto es seguido por el capítulo (6) y luego el número o números de línea (17-18).

3 Para el tratamiento reciente del misticismo platónico, ver Versluis, 2017.
} 
por extraño que parezca, en su prefacio a la traducción de Plotino: "debes creer que Platón mismo está hablando de Plotino cuando exclama: 'Este es mi Hijo, mi amado, a quien le corresponde mi favor, escúchalo a él' (Mt 17:5)" ${ }^{4}$ (Creuzer, 1835: xi).

\section{Siglos XV y XVI: texto y traducciones}

Para los propósitos de este capítulo podemos decir, entonces, que la erudición moderna sobre Plotino comenzó con Ficino, Pico della Mirandola y otros en el Renacimiento, y particularmente con la traducción de Ficino de las Enéadas, publicada en 1492 (junto, por supuesto, con sus obras sobre Platón, Porfirio, Jámblico, Proclo y muchas otras figuras antiguas). ${ }^{5}$ En la Edad Media occidental antes de la época de Ficino (O'Meara, 1992: 58-59), Plotino era prácticamente desconocido. Ninguna de sus obras había sido traducida, y las primeras traducciones como la de Mario Victorino en la Antigüedad tardía se habían perdido. Ya sea que figuras como Juan Escoto Eriúgena o Guillermo de Saint-Thierry conocieran o no a Plotino, las resonancias plotinianas en estas obras podrían ser el resultado de elementos neoplatónicos en Agustín, Ambrosio, Macrobio, Boecio, Dionisio Areopagita, Máximo el Confesor, Gregorio de Nisa, y, aún más tarde, Proclo a través del Liber de Causis. ${ }^{6}$ Tales figuras, influenciadas por estas fuentes indirectas, incluyen a Alberto Magno, Buenaventura, Guillermo de Auvernia, Vicente de Beauvais y Meister Eckhart. Algún Plotino pudo haber sido leído en los sermones de Ambrosio o en los comentarios a Dionisio escritos por Juan de Escitópolis. Y al menos un escritor medieval, Hugo Eteriano (hacia 1166-1182), leyó de alguna forma a Plotino en Constantinopla en el siglo XII y se pueden encontrar algunos rastros en su obra, De sancto et immortali Deo (PL 202: 233c y 339b) (O'Meara, 1992: 59). Ciertamente, también la Teología de Aristóteles árabe y otras colecciones ${ }^{7}$ que contienen extractos de las Enéadas eran conocidas por la tradición islámica (Al Kindī, ${ }^{8} \mathrm{Al} \mathrm{Farabī,}$ Ibn Sina [Avicena], los Hermanos de la Pureza [Ikhwān al-Ṣafā’] y muchos otros) y por los escritores judíos medievales (Isaac Israel, Ibn Gabirol, Ibn Ezra), pero no fue traducida al hebreo antes del siglo XVI. Por lo demás, ningún trabajo directo de Plotino estuvo disponible en los siglos XV y XVI.

De este modo, la aparición de dos manuscritos de Plotino a principios del siglo XV en Florencia fue deslumbrante, uno adquirido por Palla Strozzi, a saber, el Parisinus Gr. 1976, y el otro, el Laurentianus 87.3, traído primero de Constantinopla por Giovanni Aurispa y, después de la muerte de su primer dueño, Nicolo Nicoli, comprado por Cosimo quien, a su vez, se lo dio a Ficino en Careggi en $1462 .{ }^{9}$ En este último manuscrito o en una copia hecha por Johannes Scutiatores -el Parisinus Gr. 1816-comenzó a trabajar Ficino desde 1463. Mientras Ficino pudo haber hecho una copia del Parisinus Gr. 1976 antes de 1471 en la biblioteca de Palla Strozzi, solo el Laurentianus 87.3 y su copia, el Parisinus Gr. 1816, llevan varias anotaciones diferentes de su mano. Así que, aunque usó otros manuscritos (dos colecciones de extractos de Plotino -y Platón- en

4 Cf. Mt 3:17; Mc 1:11; Lc 8:12. Ver Saffrey, 1996: 496.

5 Para una lista de personas, ver Laurens, 2012: lxxi-lxxxix.

6 El pseudo-aristotélico Liber de Causis, una adaptación de los Elementos de Teología de Proclo -como detectó Aquino (Super Librum de Causis expositio, Proem. 3. 3-10, Saffrey)- puede remontarse al círculo de Al Kindī (D'Ancona, 2010: 879).

7 Parafraseos de Enéadas IV-VI (parcialmente recopilados en una traducción al inglés de G. Lewis en H-S1 II, 1959) que incluyen: A. la llamada Teología de Aristóteles (se desconoce por qué se le atribuye a Aristóteles) en las recensiones cortas o largas, o vulgares (cuya interconexión no está clara) incluye un prólogo, 142 encabezados de capítulos (para Enéada IV.4) y 6 libros de paráfrasis para Enéadas IV-VI (quizá los comentarios y resúmenes perdidos de Porfirio. Ver Henry,1937: 310-342; Schwyzer, 1941: 216-236; Thillet, 1971: 293-302; Goulet-Cazé, 1982: 321-323), remontados a un original sirio o al traductor de Plotino del siríaco al árabe, Al Himsī, (Zimmerman, 1986: 131) o al propio Al Kindī (D’Ancona, 2010: 875, n. 2); B. la Carta de la Ciencia Divina, atribuida erróneamente a Al Farabī, incluye paráfrasis de partes de la Enéada V; C. varios materiales atribuidos al "Viejo Griego", paráfrasis de Enéadas IV-VI y, por lo tanto, paralelas a la Teología.

8 Sobre Al Kindī, ver Adamson, 2016: 26-32 y 2017; D'Ancona, 2010: 872-884.

9 Sobre esto y la biblioteca de Ficino, ver Laurens 2012: lxxi-lxxxix, especialmente lxxvii-lxxix. 
griego: Milán, Ambrosianus F 19 sup., y en latín: Florencia, Riccardianus 92, y Vat., Borg. gr. 22) (Saffrey, 1996: 491), estos otros manuscritos son todos dependientes del Laurentianus 87.3. En consecuencia, Ficino no llevó a cabo una comparación crítica de manuscritos, sino que tuvo que recurrir a conjeturas-divinatio, como dice Saffrey (1996: 505), por más brillantes que estas conjeturas pudieran haber sido. Por supuesto, también le debemos a la incisiva comprensión marsiliana de Plotino la división del texto en capítulos con títulos y encabezados que expresan el desarrollo de las ideas que usamos hasta hoy. Su traducción de Plotino con comentario fue publicada en 1492 y fue ampliamente utilizada por eruditos en Italia y en otros lugares, incluyendo a Giordano Bruno y muchos otros. En el siglo XVI se reimprimió cinco veces y su comentario se reimprimió por separado tres veces más.

En 1580, la traducción latina de 1492 de Ficino se utilizó en la editio princeps del texto griego que apareció en Basilea bajo la dirección de Pietro Perna. El texto fue preparado para Perna por un editor desconocido $\left(\mathrm{H}-\mathrm{S}^{1}\right)$ (identificado por O'Meara [1992: 59], sobre la base del prefacio de Perna, folio $3 \mathrm{~V}$ y folio 203V, como Doménico Montesoro de Padua), que consultó cuatro manuscritos. ${ }^{10}$

También en 1519 apareció Plotino encubierto a través de la versión larga de la Teología de Aristóteles traducida al latín y luego incorporada a las ediciones de Aristóteles publicadas por A. Jacobus Martin (Lyon, 1578), Joaquín Perión (1580) y Claudio Marnio y Johannes Aubrius (Frankfurt, 1593) y de diferentes maneras por otros. La autoría de la Teología no fue rechazada hasta Lutero (1483-1546) y Pierre de la Ramée (15151572) en el siglo XVI, y no remonta a las Enéadas de Plotino hasta Thomas Taylor en 1812. No parece que hayan aparecido traducciones vernáculas de Plotino en estos siglos, excepto quizá por un comentario perdido atribuido a Paulus Scalichius (15341575) (O'Meara, 1992: 55-73). El texto de Perna, entonces, junto con "Plotino" bajo el disfraz de "Aristóteles", pero con menor consecuencia, fue fundamental para el siglo XVI hasta el siglo XIX, cuando surge un texto verdaderamente científico sobre la base de todos los manuscritos y la evidencia indirecta con Paul Henry y HansRudolph Schwyzer, siglos que por muchas razones -incluidas las que mencionamos anteriormente- fueron a veces muy desfavorables para la recuperación de Plotino por parte de Ficino.

\section{El papel oculto de Plotino durante el eclipse medieval: introduc- ción}

En el prefacio a su edición de Plotino de 1857, Bouillet señala la influencia a menudo oculta de Plotino en Alberto Magno, Tomás de Aquino e incluso Dante, una influencia vinculada a las discusiones del pensamiento peripatético en la filosofía judía e islámica, a menudo por el Fons Vitae de Ibn Gabirol; también nota la influencia de Plotino en escritores modernos como Bossuet, Fénelon, Malebranche y Leibniz, quienes "reproducían, incluso sin conocimiento, doctrinas [plotinianas/neoplatónicas], cuya procedencia frecuentemente ni siquiera sospechaban". ${ }^{11}$ Algo así es lo que discutiré aquí en relación con el descubrimiento de un Dios infinito, un único cosmos infinito y, finalmente, un ser infinito increado, como indiqué anteriormente que fue el caso de Meister Eckhart, Nicolás de Cusa y Giordano Bruno (sobre los principios plotinianos básicos de que el centro de todas las cosas está en todas

10 Ver Henry 1948 (Manuscrits): 295-319; H-S1 I, Praefatio xxv-xxvi.

11 "Ce n'est pas que tous ces auteurs aient eu sous les yeux les écrits mêmes de Plotin ou de ses disciples; mais, nourris comme ils létaient de la lecture des Pères de l'Église, dont plusieurs étaient platoniciens, et dont quelques-uns, comme on l'a vu, avaient fait à Plotin des emprunts directs, familiarisés d'ailleurs avec la théologie scolastique dans laquelle avait passé et s'était pour ainsi dire incorporée une grande partie des doctrines néoplatoniciennes, ils reproduisaient, même à leur insu, ces doctrines, dont le plus souvent ils ne soupçonnaient pas la source” (Buillet, 1857: xxxii-xxxiii). 
partes y en ninguna parte, y de que hay algo en nosotros que no ha descendido). En otras palabras, argumentaré que, en ausencia de Plotino, Meister Eckhart y Nicolás de Cusa -aunque de diferentes maneras- llevaron importantes elementos del pensamiento de Plotino a ciertas conclusiones lógicas, y que mientras Giordano Bruno -con el texto y la traducción de Ficino de Plotino en la mano- pareció haber destruido la jerarquía neoplatónica, lo que hizo de hecho fue desenredar una hebra particular de esa tradición que podría remontarse hasta el mismo Plotino. Tomaré estas cuestiones en el siguiente orden:

a) primero, el carácter general del neoplatonismo: la disposición jerárquica de las denominadas hipóstasis (el Uno o el Bien, el Intelecto y el Alma) y los dos mundos característicos, los mundos inteligible y sensible, en contraste con la teoría del "universo único";

b) segundo, el uso de términos como "no contracto" y "contracto" por Nicolás de Cusa, desarrollado, tal vez, por Duns Scoto (1265 / 66-1308) y John Peckham (1230-1292), pero prefigurado en Plotino y la tradición anterior;

c) tercero, la convergencia final del Uno y la materia en Giordano Bruno; y

d) finalmente, la cuestión de un yo infinito increado y un amor autocausal divino. No tendré espacio para esto, pero me gustaría señalar su importancia.

\section{Un Plotino hipotético}

Entonces, si Plotino hubiera estado vivo en la última parte del siglo XVI, mientras Giordano Bruno todavía escribía, y si hubiera podido rememorar los 1200 años transcurridos desde su muerte en 270 , si dejamos de lado a los neoplatónicos inmediatos, Porfirio y Jámblico después de su propio tiempo, ¿qué hubiera pensado sobre todo esto?

Sé que habría aplaudido a la gran tradición de los comentarios, ya que era parte de la práctica en su propia escuela leer a Alejandro, Aspasio y otros comentaristas y pensar críticamente y creativamente a través de ellos. Los comentarios de Proclo, su Teología platónica y especialmente los Elementos tanto de teología como de física lo habrían intrigado. Aunque, sobre la base del testimonio de Porfirio en la Vida y del propio método de Plotino en las Enéadas, podríamos suponer que habría desaprobado enfoques excesivamente dogmáticos; podría haber visto los Elementos en particular como parte de la tradición platónica more geometrico y tal vez inspirado por el Libro VI de la Física de Aristóteles.

Después de tratar con cristianos y gnósticos en seminarios propios y durante su vida de escritor, pudo haberse sorprendido de las obras de Ambrosio, Victorino, Agustín, Dionisio y Eriúgena, al ver cómo gran parte de su pensamiento podía ser apropiado sin esfuerzo por los cristianos. Pero entonces, si Orígenes de Alejandría realmente había estudiado con él bajo Amonio Saccas, tal vez no hubiera estado tan asombrado, ya que un componente cristiano habría estado allí desde el principio. Y, por lo tanto, ¡incluso Plotino podría haber pensado que Dionisio era anterior a él! Podría haber querido discutir algo con Evagrio Póntico y otros de la tradición del desierto -sin mencionar a los otros Capadocios, especialmente Basilio y Gregorio de Nisa, y luego a algunos de los pensadores posteriores enraizados en Constantinopla- especialmente sobre la cuestión de la Trinidad, porque él mismo había argumentado que el Bien -y el Intelecto- debía ser causa y amor de Sí mismo y, por lo tanto, había provisto inconscientemente dos modelos trinitarios para el pensamiento futuro. 
El método de Nicolás de Cusa podría ayudarnos aquí a adivinar, ya que aunque es crítico con las Formas platónicas, tiende a seguir los caminos trazados por Platón y Aristóteles, Gregorio de Nisa, Boecio y por encima de todo Dionisio (De Venatione Sapientiae 124). Como habitante de la ciudad imperial de Roma, Plotino estaría consternado por la caída del Imperio de Occidente, aunque tal vez no excesivamente sorprendido, dado el peso de la guerra y la inmigración en los cien años anteriores a su muerte. Sin duda se habría entristecido por la muerte prematura del enormemente talentoso Boecio, pero estaría encantado de ver cómo el legado del platonismo floreció en la Consolación de la Filosofía y otras obras. Ciertamente se sorprendería, como todavía hoy lo estamos, de ver cómo toda la tradición griega, después de la caída de las escuelas de Atenas y Alejandría, se transformó notablemente, en parte a través de su propio pensamiento bajo el nombre de Aristóteles, junto con el Aristóteles real y Alejandro de Afrodisia, Proclo y más, en la escuela de Al Kindī, y transmitidos a Saadya Gaon, Isaac Israel, Ibn Gabirol (Avicebron), en la tradición judía, y a Al Farabi, Ibn Sina, Ibn Tufayl, Ibn Rushd, Al ‘Arabi, Suhrawardi y muchos otros, en la tradición islámica, solo para ser retraducidos de nuevo a la tradición cristiana y causar tanta dificultad, desde las acusaciones de panteísmo a los problemas sobre el alma y el intelecto y Dios o el Uno. Creo que pudo haber sentido simpatía por Tomás de Aquino antes de su confrontación con Siger de Brabante y los averroístas, a pesar de entender por qué Ibn Rushd había postulado la unidad incluso del intelecto potencial.

Ciertamente, notará que la Summa Theologica de Aquino se estructuró sobre el modelo neoplatónico de Permanencia, Procesión y Conversión, y estaría de acuerdo con Proclo, Dionisio, Aquino y Nicolás de Cusa en al menos tres cuestiones principales: a) primero, que mientras no podemos saber nada sobre la naturaleza de Dios, podemos conocer cosas significativas acerca de Dios desde su creación; b) segundo, que la nesciencia, la docta ignorancia y el reconocimiento de lo incomprensible es el comienzo de la sabiduría; y c) que no solo no podemos conocer la naturaleza de Dios, sino que el completo autoconocimiento para los seres humanos o una reditio completa no es posible en esta vida.

Sin embargo, de ninguna manera está claro lo que habría pensado acerca de los puntos de vista posteriores sobre el Intelecto (y el alma desde la perspectiva de Intelecto): ¿mi alma es mía o es parte de todo el mundo inteligible, y si es así, en qué sentido? A la luz de la influencia de Aristóteles y Alejandro sobre Al Farabi, Ibn Sina, Ibn Rushd, Alberto Magno y Tomás de Aquino, ¿dónde se sitúa el intelecto "agente"? ¿Compartimos, i.e. participamos en un intelecto agente?, ¿está el intelecto agente separado de todos los intelectos o es común para todos?, y ¿qué pasa con el intelecto potencial que Ibn Rushd supuso que era uno para todos los seres humanos? En otras palabras, ¿cómo le habría ido a este hipotético Plotino a partir de su eclipse en la Edad Media? El problema de la "reconciliación" entre Platón y Aristóteles se convirtió en el problema de la "reconciliación" entre Aristóteles y Plotino. ${ }^{12}$

\section{Las tres hipóstasis y un solo universo}

Así que volvamos a las Enéadas mismas y comencemos con el carácter general del neoplatonismo plotiniano, es decir, la jerarquía de tres hipóstasis esbozadas de manera famosa en Enéada V.1 [10], 8-9, y la visión de dos mundos de Platón que impregna las Enéadas como un todo. Esta es por supuesto la visión tradicional del pensamiento de

12 George Karamanolis ha mostrado cómo Amonio, Porfirio (quizá Plotino) y otros pudieron haber visto la "reconciliación" de Platón y Aristóteles no como una identidad de pensamiento, sino como pertenecientes a la misma escuela o hairesis, es decir, no symphonia o acuerdo comprehensivo, sino permitiendo las diferencias entre ellos, aunque Porfirio, por ejemplo, cree que estas diferencias pueden ser a) perspectivistas o triviales, b) malas interpretaciones de Platón por parte de Aristóteles, o c) malas interpretaciones de Aristóteles por parte de los intérpretes posteriores (Karamonolis, 2006: 322-323). 
Plotino, y es correcta, incluso si la palabra "hipóstasis" no tiene un sentido técnico para Plotino. ${ }^{13}$ De hecho, Plotino ve el mundo de forma bastante diferente a nuestro pensamiento moderno típico. Tendemos a considerar que los cuerpos son lo único real, porque vivimos en un universo materialista, impulsado por el dinero y cargado de hechos científicos; e incluso si admitimos que los organismos necesitan un principio organizador o alma, pensamos en el alma -si es que la pensamos- como estando de alguna manera en el cuerpo. Plotino ve la organización corporal y la materia meramente como la punta de un iceberg mucho más vasto: el alma no está en el cuerpo tanto como el cuerpo en el alma (como dice Platón en Timeo 36d-37c). Los cuerpos, la naturaleza y todo el mundo físico están enraizados en tres océanos mucho más grandes o principios originarios: Todo Alma, Todo Intelecto y el principio fundamental que Plotino llama simple: el Uno o el Bien (ver para el Bien VI.7 [38], 42: 21-24); y para ambos veáse el título de VI.9 [9]: Sobre el Bien o el Uno). Déjenme ilustrar esto con una poderosa imagen que Plotino usa para la relación alma-cuerpo:

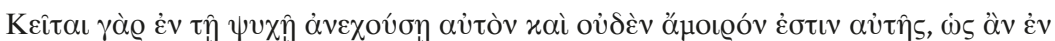

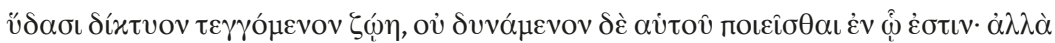

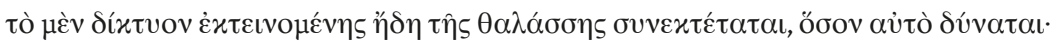

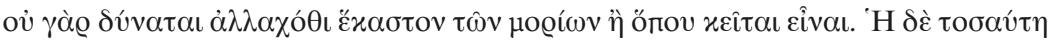

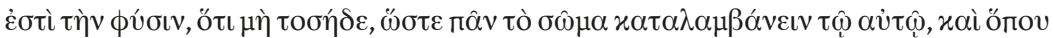

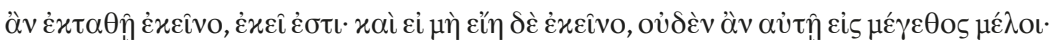

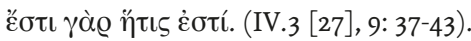

Si esto es verdad del alma, lo es aún más del Intelecto y del Uno. El Uno es infinito, más vasto que el Intelecto o el Alma (VI.7 [38], 32-35).

Sin embargo, esta no es la única perspectiva plotiniana de las hipóstasis. Hablar del Uno, el Uni-Múltiple como Intelecto, y el Uno-en-lo-Múltiple como Alma (como lo hace Plotino en V.1 [10]) no es hablar de jerarquía espacial o de un agregado $(1+2$ +3) sino, de hecho, para hablar de una realidad única jerarquizada, como Plotino dice de manera ambigua de hen y hen on en su gran obra sobre la omnipresencia, VI.5 $[23] .{ }^{14}$ De hecho, hablar en términos modernos de "alma y cuerpo" o de una relación alma-cuerpo es falso ya que el alma-cuerpo no es un agregado material o una adición formal, como Sócrates argumentó convincentemente en el Fedón 95a-102a -es decir, no alma $y$ cuerpo, aunque podemos pensarlo post rem de esa manera- o como Plotino dice en VI.3, 8, podemos pensar en la "sustancia sensible" como sustancia falsa cuando se la considera como symphoresis de cualidades y materia. ${ }^{15}$

En realidad, sin embargo, la ousia -que podríamos traducir legítimamente como "cosa realmente genial" (really cool stuff)- es el umbral a partir del cual las cosas se vuelven identificables, definibles y orgánicamente reales. Desde esta perspectiva, hay una ventana desde la percepción hacia la comprensión. Como dice Plotino en VI.7 [38], 7: 30-32: "aquí" percepciones son entendimientos oscuros, "alli" entendimientos son percepciones claras. ${ }^{16}$ En consecuencia, a menudo encontramos dos puntos de vista en las Enéadas que los comentaristas a veces han llamado Intelecto stricto sensu e Intelecto latiori sensu, es decir, Intelecto como Intelecto, en el que cada nous es tanto él mismo

13 Acerca del sentido de hypostasis en y luego de Plotino, ver Narbonne et. al., 2012: cxvii-cli.

14 Ver especialmente Enéada VI.5 [23], 1-4.

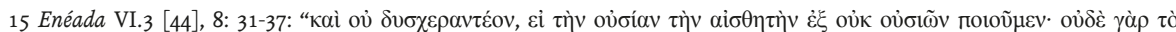

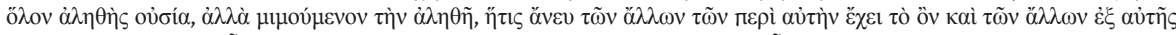

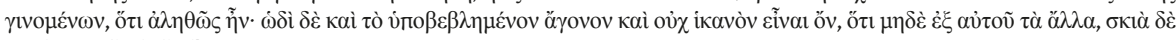

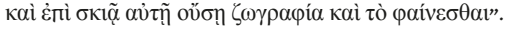

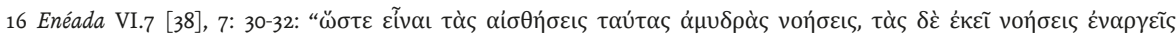

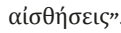


como todo lo demás, ${ }^{17}$ y el Intelecto en el sentido más amplio que contiene todas las sustancias -de hecho, todo lo que puede ajustarse a un lógos, como dice Plotino en VI.2, $21 .{ }^{18}$ Tanto es así que Plotino incluso afirma que la materia y las cualidades están en lo inteligible. ${ }^{19}$ No hay, entonces, sustancia sin todas las sustancias, y esto se aplica también a la materia, ya que, según Plotino, hay un logos de la materia (III.3 [48], 4: 37-40), ${ }^{20}$ y también la materia, como dice Plotino en V.8 [31], 7: 23-24, es "una última forma". En otras palabras, no existe un mundo sensible sin lo Inteligible que lo convierte en un mundo. No hay imago sin el exemplar en el que tiene su ser completo. Las categorías del Organon de Aristóteles, por el contrario, son para Plotino abstracciones post rem, razón por la cual las rechaza como principios estructurantes e inteligibles en las llamadas obras lógicas, Enéada VI.1-3. Pero esto no significa que los predicados entendidos de manera sustancial no puedan interpretarse de manera diferente: las cualidades, por ejemplo, son cualidades en la materia (II.6 [17], 1), pero también pueden ser actividades, y en el último caso, son seres inteligibles. ${ }^{21}$ Así que mi primera tesis es esta: a pesar de la jerarquía de hipóstasis y la distinción entre los universos inteligible y sensible, el mundo de Plotino es Uno en su origen: en cualquier punto, el Todo está presente o virtualmente presente; de hecho, la suave presencia del Uno es tan íntima que ni siquiera nos damos cuenta, pero el Bien está abierto "cuando sea que alguien lo desee o lo quiera" (V.5 [32], 12:33-34).

Entonces, al hablar de las hipóstasis y los intermediarios entre lo Uno y nosotros, debemos tener en cuenta que Plotino en realidad no aprueba las múltiples hierofanías hipostáticas e inter-hipostáticas de los gnósticos -setianos o valentinianos. En contraste, para Plotino está todo presente inmediata y dinámicamente, incluso si lo experimentamos de una manera desplegada o si nos equivocamos por completo; e incluso esto no es suficiente, ya que lo Uno como poder de todas las cosas está presente en todo de un modo no sustancial, ya sea como dormido, despierto, racional, no racional, potencialmente oculto, incluso insignificantemente posible.

Y esto me lleva a mi segunda tesis: a diferencia de muchos expertos y no expertos modernos en neoplatonismo, Nicolás de Cusa, incluso sin acceso directo a Plotino, alcanza un "Plotino" (y gran parte de la antigua tradición platónica) profundamente correcto, al menos en la hipótesis del universo único. En un pasaje enfático, aunque difícil, de De dato Patris luminum -obra suya a la altura del Génesis, el Timeo y la Enéada VI.7 [38], 1-7, Nicolás escribe lo siguiente:

Sed quia data aeternitas non fuit nisi contracte recepta, hinc aeternitas sine principio principiative recepta exsistit. Mundus igitur non habet principium, ut in ipso aeternitas est omne esse eius. Sed quia non est recepta aeternitas nisi principiative in descensu mundi, tunc mundus non est aeternitas absoluta sed aeternitas principiative contracta. Aeternitas igitur mundi principiata est et aeternus mundus factus est, neque est alius mundus, qui apud patrem est aeternus, et alius, qui per decensum a patre est factus, sed idem ipse mundus sine principio et principiative per descensum in esse proprio suo receptus [...] sed ut in descensu a patre in esse proprio receptus est, transmutabilis est in vicissitudine ombrationis instabiliter fluctuans, quasi mundus sit deus transmutabilis in vicissitudine obumbrationis, et mundus intransmutabilis et absque omni vicissitudine obumbrationis sit deus aeternus (De dato Patris luminum III: h IV.106).

\footnotetext{
17 Ver, por ejemplo, Enéada V.8 [31], 4.

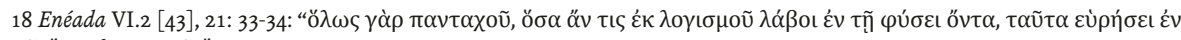

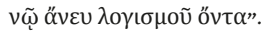

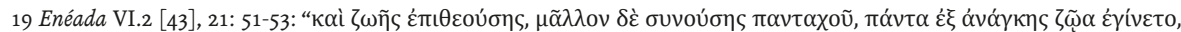

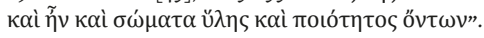

20 Ver también Enéada III.8 [30], 2: 23-25.

21 Comparar Enéadas II.6 [17], 2 y II.3 [37], 3.
} 
But because eternity has not been given except as received in contracted form, eternity without a beginning stands out as an eternity in a beginning mode. Therefore the world does not have a beginning in so far as its entire being is eternity in God himself. But because eternity has not been received except under the mode of beginning in the descent of the world, then the world is not absolute eternity but eternity contracted in a beginning mode. Eternity therefore is the beginning mode of the world and an eternal world was made, nor is there one world which is eternal with the Father, and another different world which has been made through descent from the Father, but the very same world without beginning and in beginning mode received through descent in its own proper being [...] but as in descent from the Father it has received in its own being, it is changeable, oscillating unstably in the changing mode of a shadow, as if the world were a changeable, shadow-form God, and the unchangeable, shadow-free world were the unchangeable God.

Esta es mi traducción del texto en latín que, con Jasper Hopkins, evita las malas traducciones de Jacobi (Hopkins, 1983: 33-57). Dios o la eternidad de Dios no es el "ser" directo, individual o específico de este mundo cambiante y de todo lo que está en él. Cada cosa en este mundo y el mundo mismo tiene su propio ser, y, sin embargo, precisamente como en Platón y Plotino, el ser real de la imagen depende y consiste enteramente en su ejemplar. En esto insiste Nicolás, evidentemente con el Timeo en mente: es como si este mundo fuera una sombra o imagen del mundo de un paradigma eterno identificado en De dato Patris luminum con el Demiurgo; Timeo lo llama un "dios bendito"; Nicolás lo llama aquí un "dios sombrío" para indicar que está pensando en Platón. ${ }^{22}$ Sin embargo, como con Plotino y mucho antes con Aristóteles que criticó a Platón precisamente en este punto -es decir, por duplicar innecesariamente mundos-, si imaginamos que hay dos mundos, un mundo inteligible $y$ uno sensible, malinterpretamos tanto a Platón como a Aristóteles y hacemos de la creación, la producción o el llegar-a-ser un agregado cualitativo o cuantitativo, mientras que la sustancia no puede ser "A más B", como Sócrates había argumentado en el Fedón y como insistió correctamente Aristóteles en Metafísica VII.17 (Z); la sustancia como forma no puede ser un agregado de A más $\mathrm{B}$ o AB, concluye Aristóteles, sino algo diferente, una sílaba, es decir, un nuevo significado orgánico: heteron ti. ${ }^{23}$

Por lo tanto, debe haber un mundo único entendido de diferentes maneras, como ejemplar y semejanza, como Dios y como imagen. En el pasaje anterior, por un lado, Nicolás está reinterpretando de manera revolucionaria a Platón, Aristóteles, Plotino y la tradición posterior, pero al mismo tiempo interpretándolos de modo parcialmente correcto, en sus propios términos. De hecho, esto tiene que ser enfatizado ya que, hasta donde yo sé, es un malentendido casi universal del neoplatonismo: como sustancia, puede haber solo un mundo, tanto para Plotino como para Nicolás. Sin la ousia, el mundo sensible no es nada; sin la ousia entendida como inteligible, la sustancia sensible es solo accidentes y materia. Este es el último punto de la crítica de Plotino en VI.1-3 [42-44].

Por otro lado, la visión cusana de la realidad es muy diferente de aquella del pensamiento pagano antiguo, ya que solo hay necesidad de un ejemplar, Dios, no de muchos ejemplares -Formas- y por lo tanto no hay universo inteligible ni alma del mundo como tal. En cambio, como vemos en De docta ign. II: h I.148-149: no llegamos al máximo desde aquí, argumenta Nicolás; en cambio:

22 Para un lenguaje similar, ver De docta ign. II: h I.134: “... quasi creatura sit deus occasionatus... ut omnis creatura sit quasi infinitas finite aut deus creatus".

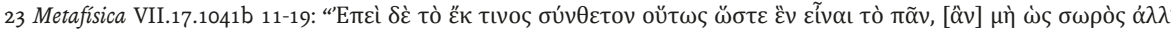

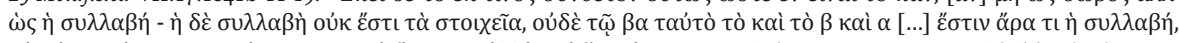

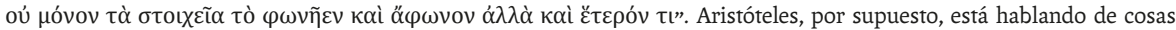
sensibles, pero quiere decir que la sustancia en el sentido de la forma no es los materiales constituyentes sino algo nuevo. Evidentemente, las hipóstasis de Plotino no pueden entenderse como elementos o constituyentes de un todo mayor, sino que, mutatis mutandis, aplica el mismo principio. La sustancia como inclusiva de todo lo sustancial no puede ser un agregado hipostático sino un Uno-múltiple. 


\begin{abstract}
Nam ostensum est non perveniri ad maximum simpliciter, et ita non posse esse aut absolutam potentiam aut absolutam formam sive actum, qui non sit Deus; et quod non sit ens praeter Deum non contractum, et quod non est nisi una forma formarum et veritas veritatum, et non est alia veritas maxima circuli quam quadranguli. Unde formae rerum non sunt distinctae, nisi ut sunt contracte; ut sunt absolute, sunt una indistincta, quae est Verbum in divinis (De docta ign. II: h I.148).
\end{abstract}

Entonces Nicolás, al igual que Basilio de Cesarea y otros después de él, insiste en que las hipóstasis no son numerables cuantitativamente. ${ }^{24}$ En otras palabras, no son agregados, algo que el mismo Plotino sigue en su metodología ya que a diferencia de los gnósticos setianos -Jámblico y Proclo-, ${ }^{25}$ pero al igual que Porfirio, tiende a menudo a "plegar" las hipóstasis ${ }^{26}$ para que el Uno esté inmediatamente presente al sí-mismo individual. ${ }^{27}$ De hecho, la lógica del pensamiento de Proclo y Dionisio insiste en que el poder del Uno es inmediato para los individuos, más "penetrante" que el de las hénadas, el Intelecto o el Alma en el caso de Proclo, ${ }^{28}$ más real y henádicamente unificado que cualquier otra presencia auxiliar, en el caso de Dionisio. ${ }^{29}$ Para Nicolás, entonces, cuando visitamos a Dios en su Palabra o Espíritu, efectivamente somos "indistintos". Ya no hay una relación de A y B mediada a través de un Mundo Inteligible, sino algo más inmediato, y algo con lo que Plotino, Jámblico y Proclo también se comprometieron, si bien de diferentes maneras.

\title{
VI. Complicación-explicación, incontracto-contracto: un Dios infini- to y un universo infinito contracto
}

¿Qué pasa con el lenguaje de la contracción y la incontracción, la complicación y la explicación, que encontramos a lo largo de todo el corpus de obras de Nicolás? He sugerido anteriormente que los términos provienen de Duns Scoto y John Peckham, pero en realidad no sé dónde se originan, excepto por el hecho de que de alguna manera indirecta deben estar relacionados con Plotino, y más específicamente con la Enéada VI.7 [38], ya que se usan por primera vez en la reevaluación crítica de Plotino de la representación de Platón del Demiurgo en el Timeo. Un Ser Divino, sostiene Plotino, no puede necesitar deliberar, planificar o razonar, ya que esto es un defecto. En cambio, aquello que se despliega o explica en nuestra experiencia como seres sujetos al continuo espacio-temporal está "anteriormente" complicado o contenido en la actividad completa del Intelecto Divino; ${ }^{30}$ podemos ver esto incluso en nuestra experiencia discursiva presente de las formas en la naturaleza, "si explicas a sí misma

24 Basilio, De Sancto Spiritu XVI.38 (SC 17bis, Pruche); ver Corrigan, 2008. En contraste con la segunda y tercera hipóstasis de Plotino, el mundo creado, para Nicolás, "non potest creatura utcreatura dici una, quia descendit ab unitate, neque plures, quia eius esse est ab uno; neque ambo copulative. Sed est unitas eius in quadam pluralitate contingenter" (De docta ign. II: h I.100).

25 Ver Turner, 2001.

26 Ver Armstrong, 1967: 266-267. Esto se encuentra más pronunciado en Porfirio (Lloyd, 1967: 287-288).

27 Ver Enéadas V.5 [32], 12: 33-34; V.3 [49], 14: 8-19; VI.9 [9], 10: 14-20 y 11: 23-25; VI.7 [38], 35: 7-16.

28 Proclo, In Alc. 330.7: “más penetrante" (drimuteros); cuanto más alto es el principio, más extenso o más penetrante es su efecto; cf. ET prop. 57. Para un comentario, ver Dillon, 1973: 236-38 (sobre Olympiodorus, In Alc. 110.13 ss).

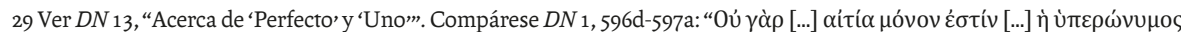

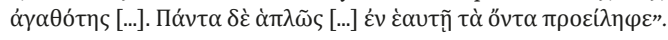

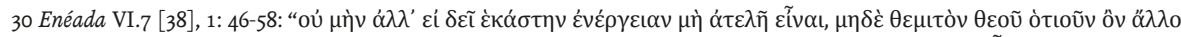

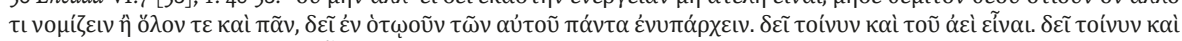

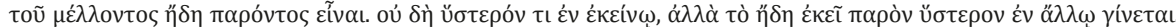

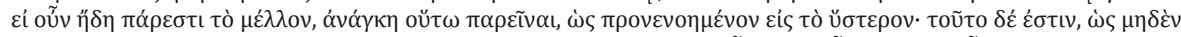

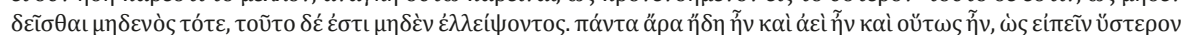

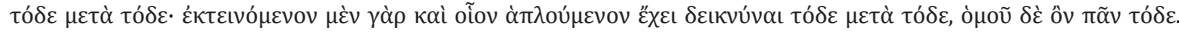

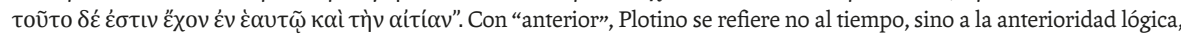
es decir, lo que está coimplicado en el mundo inteligible "puede mostrar esto después de esto, pero como un todo es enteramente esto; lo que significa que tiene su causa también en sí mismo" (ibid. 56-58). 
la forma, encontrarás la razón". ${ }^{31}$ Incluso en el mundo sensible la mutua causalidad implicativa de todas las cosas que podemos resolver mediante el razonamiento discursivo manifiesta, en el orden explicado, la total naturaleza simultánea implicada de la actividad Divina (VI.7 [38], 2: 1-37). ${ }^{32}$ Por lo tanto aquí, en el nivel inteligible, y a partir de nuestra experiencia de la razón discursiva en el mundo sensible, existe un modelo para comprender cómo el complejo orden del devenir puede en realidad desarrollarse a partir de un orden superior y más simple del ser mismo.

Este es exactamente el lenguaje que utiliza Nicolás. ${ }^{33}$ En De Visione Dei, por ejemplo, la vista de Dios ve "toda la página", "todo alrededor, arriba y abajo de todas las cosas a la vez". La eternidad complica y explica todas las cosas (Hopkins, 1983: 46); por el contrario, nosotros solo vemos las partes sucesivamente. No obstante, al igual que en la forma de Plotino que se despliega en el tiempo pero que podemos replegar sobre sí para ver el nexo complejo e inteligible de la causalidad mutua incluso en el plano sensible, así también en el simplicissimus conceptus de Nicolás todos los movimientos y sonidos se complican (complicantur) de tal manera que "lo que ocurra sucesivamente" es "el despliegue (explicatio) del concepto". La temporalidad, en este sentido, no surge de ningún momento anterior, sino de la explicatio de una complicatio eterna (De visione Dei: h VI.46). Nicolás vincula esto implícitamente, como lo hace Eckhart explícitamente, con Agustín: tu eras intus, ego foris: "cuando te descubro como un poder que envuelve todas las cosas, voy hacia dentro. Cuando te descubro como un poder que va hacia fuera, voy fuera" (Deutsche Werke I.47). De hecho, también, mientras que el lenguaje de la contracción/incontracción, de lo absoluto y lo relativo, no está en Plotino, la identificación de lo complicado con lo simple y unificado ${ }^{34}$ sí se encuentra exactamente en Plotino (VI.7, 1). Por lo tanto, afirmo que la Enéada VI.7 es curiosamente (ya sea a través de Proclo o de Juan Filópono o de otros intermediarios) una fuente de la distinción cusana complicado/explicado; $\mathrm{y}$, como un corolario adicional a esta tesis, sugiero que la noción de contracción, en general, se relaciona indirectamente con el uso de Plotino de la palabra synhypostasis (que solo aparece dos veces en las Enéadas y solo en este tratado, VI.7-aquí en los capítulos 1-2 y posteriores en el capítulo 40) para significar la realidad co-hipostática complicada/explicada que es simultáneamente inteligible en un sentido amplio, y en un sentido aún más amplio en la medida en que llega directamente a las cosas sensibles -en un sentido, un despliegue de una realidad simple complicada; en otro sentido, una contracción de la totalidad inteligible en una forma determinada. Plotino pregunta qué es el ser humano, y responde: es la forma la que hace a este ser humano, inherente, no separada;y para aquellos que definen la esencia incluso de formas materializadas, este es el método correcto de proceder (VI.7, 4). ${ }^{35}$ En otras palabras, la "estidad" de cualquier particular sensible es

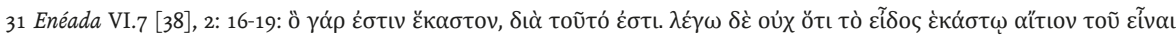

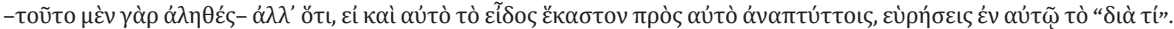

32 Ver también Enéada VI.8 [39], 14: 16-31.

33 Sobre el rango de significados de contractio, ver Hopkins, 1983: 99-101.

34 De visione Dei: h VI.6o: “... tu es ipsa infinitas esse omnium complicans simplicissima virtute, quae non foret infinita nisi infinita unita".

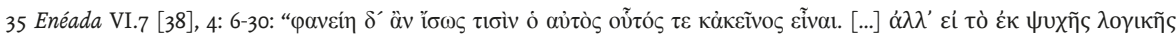

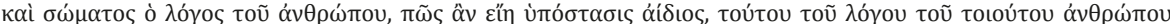

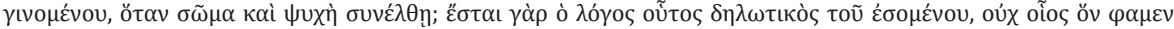

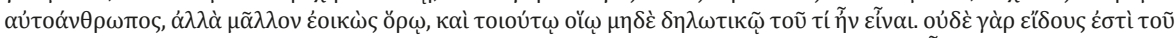

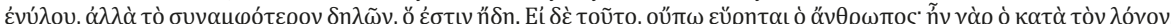

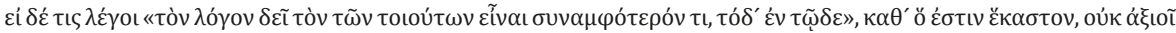

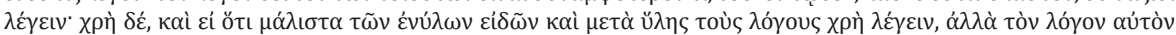

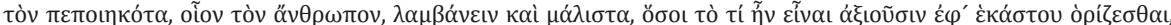

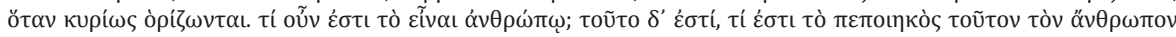

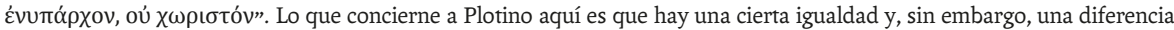
entre el ser humano inteligible y el sensible, en la medida en que este ser humano sensible tiene que definirse en relación

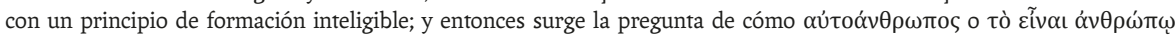
pueden estar "en" este sensible ser humano. ¡La única solución es que debe ser la forma productora presente en la cosa, no separada, que hace de este ser humano esta entidad determinada, definible, pero real! 
la forma causal en la cosa determinada, lógicamente anterior a ella y, por lo tanto, una ventana abierta sobre toda la realidad inteligible. Plotino no habla de "contracción", solo "co-hipóstasis", pero es relativamente claro: en las cosas sensibles individuales, la forma que las hace ser lo que son es una co-hipóstasis o complicación-despliegue, quizás en diferentes niveles, del simple Ser "absoluto" o "desvinculado". En su crítica a Avicena de la emanación a través de la inteligencia, el alma y la naturaleza, en lugar de una simple emanación del máximo contracto desde el máximo absoluto (De docta ign. II: h I.116: per simplicem emanationem maximi contracti a maximo absoluto) -como Plotino realmente hace en VI.7, 1-2- Nicolás indica que algo así como esta contracción inmediata a "esto" es lo que tiene en mente cuando la define en el mismo pasaje por primera vez en $D D I$ de la siguiente manera: Contractio dicit ad aliquid, ut ad essendum hoc vel illud (ibid.); y acerca de la opinión de Aristóteles de que no hay nada entre agente y paciente, productor y producto -a menudo citado por Plotino como uno de sus principios fundamentales- Nicolás de Cusa insiste, contra cualquier noción de un anima mundi, en el Verbum cristiano en el que Dios hace todas las cosas. ${ }^{36}$

\section{VII. ¿Una crítica "neoplatónica" al neoplatonismo?}

Sin embargo, Nicolás en el $D D I$ también hace algo muy diferente de Plotino, algo con lo que, no obstante, creo que nuestro hipotético Plotinus redivivus finalmente tendría que estar de acuerdo. Nicolás desarrolla una línea de pensamiento que parece, a primera vista, directamente opuesta a muchas imágenes neoplatónicas, pero que sin embargo resuelve efectivamente sus implicaciones lógicas del modo más apropiado. En el siglo III, Plotino habitó una cosmología, como hemos visto anteriormente, que podría ser fácilmente adaptada más tarde, por la influencia de Aristóteles y Alejandro, a la imagen de esferas celestiales concéntricas enraizadas en el Primum Mobile que llega hasta la luna y es presidida por un Intelecto Agente junto con el Arcángel Gabriel. Esta es la imagen que encontramos en Al Farabi e Ibn Sina. Y, sin embargo, todo el pensamiento místico e intelectual de Plotino no estaba dirigido en realidad a la esfera concéntrica, sino que se focalizaba en la omnipresencia inmediata de la unidad y el ser (VI.4-5 [22-23]). En consecuencia, sugiero que hay una tensión oculta en el pensamiento neoplatónico entre una cosmología localizada, por una parte, y una orientación local-global de enfoque espiritual que parece muy incongruente con cualquier cosmología basada en una visión del mundo peripatética. Al mismo tiempo, por analogía con nuestras propias teorías del Big Bang, Plotino compara el surgimiento del Intelecto a partir del Uno, y del Alma a partir del Intelecto, como una expansión, un despliegue en la multiplicidad ${ }^{37}$-tal como en el pensamiento pitagórico un punto se expande en una línea, un triángulo y finalmente un cosmos de cuatro dimensiones o, de nuevo, para tomar la imagen neoplatónica más famosa, tal como un círculo que se expande o crece $^{38}$ a través de sus radios en una circunferencia. ${ }^{39}$

Nicolás hace exactamente lo contrario. A partir de la imagen geométrica de la línea infinita indivisible, entendida de forma no cuantitativa, lo que se despliega es un "infinito contracto", $4^{\circ}$ contraído por y en la curvatura del espacio-tiempo que da como

36 De docta ign. II: h I.150: "Nec cadit eo modo medium inter absolutum et contractum".

37 Para ejemplos, ver Corrigan, 2002: 149-158; y Bussanich, 1988 y 2007, passim.

38 Para la imagen del crecimiento, ver Enéada VI.8 [39], 18:12-13. Cf. Enéada III.8 [31], 8: 32-38.

39 Enéada VI.8 [39], 18: 7-22; para otros ejemplos ver Sleeman-Pollet, 1980: sub grammē, kuklos etc.

40 De docta ign. II: h I.112: "Nam ipsum contractum seu concretum cum ab absoluto omne id habeat"; ibid. 114: "Nam infinitas contracta aut simplicitas seu indistinctio per infinitum descendit in contractione ab eo, quod est absolutum [...] Quare quamvis sit maxime unum, est tamen illa eius unitas per pluralitatem contracta, sicut infinitas per finitatem". Dios es todo en todo, pero cada cosa creada tiene su propio ser; ibid. 115: "Et quia quidditas solis absolute non est aliud a quidditate absolute lunae - quoniam est ipse Deus [...] et quidditas contracta solis est alia a quidditate contracta lunae - quia, ut quidditas absoluta rei non est res ipsa, ita contracta non est aliud quam ipsa". Probablemente deberíamos entender el 
resultado triángulos, círculos y esferas en la imaginación matemática (De docta ign. I.11-12; II.1), y en la que solo hay aproximaciones de tales figuras en cosas perceptibles. ${ }^{41}$ La imagen neoplatónica se borra implícitamente, pero se articula la lógica oculta de su pensamiento. La línea infinita es tanto máxima como mínima-aquella, en términos de Anselmo, más grande o menor que la cual ninguna [línea] puede pensarse o existir. Dios es infinito; y nuestro mundo es un infinito contracto. La contracción -no expansión, explosión controlada o emanación ensanchada- encaja mejor con la lógica de la creación, si aceptamos a través de la docta ignorancia la inmensidad de Dios, que no tiene comparación alguna con un mundo contracto. ¿Qué le sugirió a Nicolás la imagen de la línea? Él menciona a Anselmo, quien comparó la verdad máxima con la rectitud infinita (De Veritate X), esto es: la verdad suprema (rectitudo) no tiene ni principio ni fin. Me pregunto si también tenemos aquí la noción de la línea indivisible que se presupone implícitamente por el símil de Sócrates de la línea dividida en República $6 .{ }^{42}$ Los recortes en la línea dividida son como contracciones de la verdad que representan el mundo desde sus propias perspectivas, pero sin embargo, inconscientemente, presupone primero una línea infinita contraída en la que la curvatura es posible (es decir, en el mundo creado) y la línea infinita sin contracción en la que no hay curvatura (es decir, Dios).

Cualquiera que sea el caso, Nicolás elabora rigurosamente la lógica de una nueva cosmología basada en la omnipresencia, a través de y en Dios, de todo ser contracto cuya imagen es falsificada por el modelo expansionista del círculo centro-radio-circunferencia o imagen esférica. Posiblemente esta lógica se ajusta mejor al pensamiento subyacente de Plotino, es decir: en lugar de esferas concéntricas con la tierra en el centro o de una circunferencia que supuestamente se contrae en un centro a través de sus radios, la contracción ocurre en la dirección opuesta. El círculo perfecto con su centro aún más perfecto es útil, pero pertenece a la imaginación matemática. En el mundo creado, no encontramos círculos perfectos, sino solo aproximaciones. Tampoco encontramos centros localizables como la tierra o incluso el sol. El centro y la circunferencia están en todas partes y en ninguna. El único centro es Dios y Dios está en todas partes, no como un centro o círculo, sino como un infinito incontracto. ${ }^{43}$ Sugiero entonces que mi hipotético Plotino habría tenido que aceptar que la cosmología de Nicolás se ajusta mejor a la lógica del pensamiento del propio Plotino que a la visión expansionista de la emanación.

Sostengo, por lo tanto, que el descubrimiento de Nicolás de un mundo infinito contracto inmediatamente enraizado en el infinito sin contracción (es decir, no separado por nada excepto por la otredad) encuadra más en los términos propios del

infinito contraído como uno máximo y por lo tanto una imagen o símbolo del infinito a la luz del De visione Dei: h VI.57-58: "Infinitum enim non est contrahibile, sed manet absolutum [...] Et sicut nihil addi potest infinito, ita infinitum non potest ad aliquid contrahim ut sit aliud quam infinitum". Sin embargo, en Plotino, la infinitud del Uno despierta una infinitud correspondiente y un infinito amor en el alma o intelecto del alma, en Enéada VI.7 [38], 33-35.

41 De docta ign. II: h I.159: "Et quoniam nos motum non nisi comparatione ad fixum [...] hinc in coniecturis ambulantes in omnibus nos errare comperimus et admiramus".

42 Para la línea infinita e indivisa que parece curvarse alrededor de un punto como una imagen para la eternidad y su

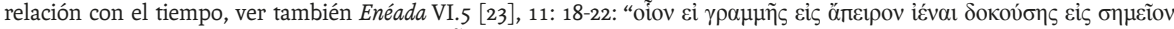

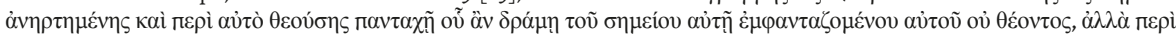

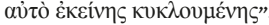

43 De docta ign. II: h I.156: dado que no podemos alcanzar ningún máximo o mínimo en ningún género, incluido el movimiento, no puede haber un mínimo simple, como un centro fijo: "Centrum igitur mundi coincidit cum circumferentia. Non habet igitur mundus circumferentiam. Nam si centrum haberet, haberet et circumferentiam [...] Cum igitur non sit possibile mundum claudi intra centrum corporale et circumferentiam, non intelligitur mundus, cuius centrum et circumferentia sunt Deus"; ibid. 162: “... cum semper cuilibet videatur, quod sive ipse fuerit in terra sive sole aut alia stella, quod ipse sit in centro quasi immobili et quod alia omnia moveantur, ille certe semper altos et altos polos sibi constitueret [...] Unde erit machina mundi quasi habens undique centrum et nullibi circumferentiam, quoniam eius circumferentia et centrum est Deus, qui est

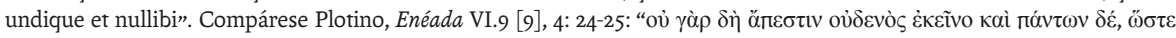

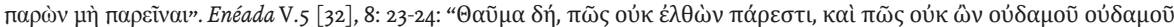

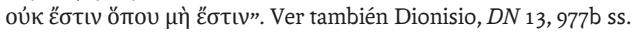


pensamiento neoplatónico que algunas de las imágenes propiamente neoplatónicas como la del centro y la circunferencia, la emanación de ríos masivos de fuentes unitarias anteriores ${ }^{44} \mathrm{o}$, como en Avicena, la floreciente jerarquía intermedia de inteligencia, alma y naturaleza (De docta ign. II: h I.116). Sin embargo, contrariamente a la opinión común (Koyre, 1957: 17), Nicolás no elimina la jerarquía: quiere en realidad entenderla de una manera no ontológica, como grados de contracción. ${ }^{45} \mathrm{Al}$ menos, así es como lo leí.

\section{Nicolás de Cusa, Plotino y Giordano Bruno}

¿Qué sucede, entonces, cuando se recupera y se traduce el texto de Plotino y se puede comparar su pensamiento directamente con este nuevo pensamiento radical de Nicolás de Cusa? Giordano Bruno ve explícitamente, quizá por primera vez, una especie de Gran Teoría Unificada: el único universo infinito complicado en Dios, pero explicado y contracto en diferentes niveles de posibilidad, no necesita de la materia concebida tradicionalmente (khora, nodriza, flujo oscilante, je ne sais quoi-substratum), puesto que Dios es Ser-Posible (como dice Nicolás en De Possest y también antes) y toda posibilidad, por contracta que sea, está en Dios y es Dios. Después de todo, Nicolás argumenta en $D D I$ que los platónicos habían postulado una materia absoluta anterior a todas las cosas que no era "coeterna" con Dios y que era "absoluta possibilitas" pero "nihil omnium actu" (De docta ign. II: h I.132). Pero si la posibilidad incontracta puede ser una especie de "posibilidad absoluta", entonces en Dios tal posibilidad debe ser Dios, ya que, como también argumenta Nicolás, toda posibilidad es contraída, pero es contraída por la actualidad (De docta ign. II: h I.137-139).

Estoy aquí simplemente sugiriendo cómo Bruno podría haber leído $D D I$, pero evidentemente con la mirada puesta en Proclo y Plotino. Si las filosofías de Platón y Aristóteles son intrínsecamente dinámicas, Plotino y Nicolás van todavía más allá. Para Nicolás, la posibilidad absoluta coincide con la actualidad: "Praesupponit enim posse fieri absolutum posse, quod cum actu convertitut, sine quo impossibile est quicquam fieri posse" (De possest: h XI/2.29). Para Plotino, el Uno no es solo dynamis

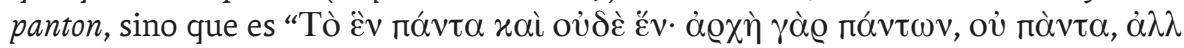

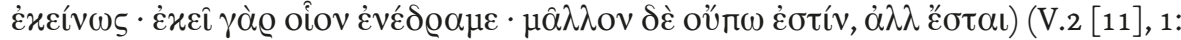
1). ${ }^{46} \mathrm{El}$ Uno es su "futuro", por así decirlo, su posibilidad absoluta. A menudo en las Enéadas, la dynamis como poder contiene implícitamente potencialidad y posibilidad, por ejemplo, el poder de ser a partir del Uno pero como una posibilidad presente en el pre-intelecto o, nuevamente, en relación con el alma y el cosmos sensible, en Enéada IV.8 [6], 5:32-36:

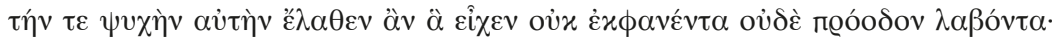

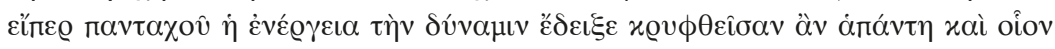

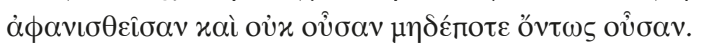

El "todavía no existen realmente" puede aplicarse por igual al ser pre-inteligible, inteligible y sensible. Para Plotino, la dynamis es anterior a la actualidad, una especie de actividad irrestricta de "estar" más allá del ser, pero presente en diferentes contracciones a lo largo del ser y el devenir. Al leer Plotino, entonces, me imagino que Giordano Bruno vio la conexión con Nicolás, pero también se dio cuenta de que la

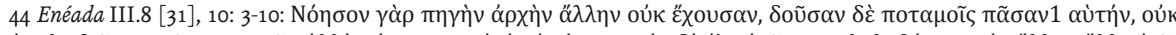

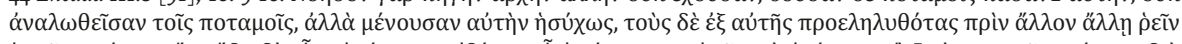

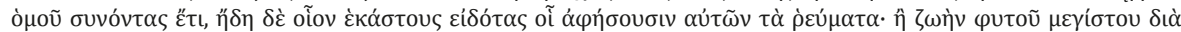

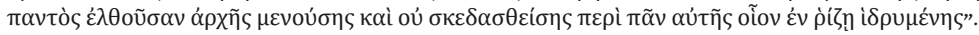

45 De docta ign. II: h I.123-126, compárese con De docta ign. III.

46 Compárese con Nicolás of Cusa, De visione Dei: h VI.48: "Tu enim, qui ocurris, quasi sis omnia et nihil omnium simul". 
conclusión más radical que podía extraerse era la siguiente: 1) si hay solamente una materia, no las dos que Plotino propone en la Enéada II.4 [12], 2) si la materia inteligible y sensible se distinguen solamente por "la forma", como sostiene Plotino en II.4, $5 ; ;^{47}$ y 3) si el Uno y la materia son del mismo modo simples -"una reunión paradójica de extremos" señalada por el propio Plotino (en VI.7 [38], 13), como señala Dodds, ${ }^{4}$ y 4) si para Proclo, "incluso la privación de formas proviene de allí" (ET 57); pero 5) si mientras para Plotino, el infinito que es el Uno se convierte en peras o límite en el Intelecto, pero está en su primer momento aún "sin forma" -para Proclo el infinito no es connatural con el Uno sino allotrion (ET 149): entonces Bruno elige a Plotino y Nicolás sobre Proclo, elimina toda distinción entre materia sensible e inteligible por innecesaria, e identifica a Dios y la materia como la posibilidad activa absoluta de todas las cosas, en la cual el poder-hacer y el poder-ser-hecho no pueden separarse.

Los argumentos de Bruno en su diálogo De la Causa, Principio et Uno son más amplios y complejos, pero esta es efectivamente su conclusión a través de un análisis crítico de Ibn Gabirol y Plotino. En palabras de Díscono, uno de los oradores:

una sia la materia, una la potenza per la quale tutto quel che è, è in atto; e non con minor raggione conviene alle sustanze incorporee che alle corporali, essendo che non altrimente quelle han l'essere per lo possere essere, che queste per lo posser essere hanno l'essere (CPU: 301).

Y finalmente, al comienzo del Quinto Diálogo, Teófilo concluye:

È dunque l’universo uno, infinito, inmobile. Una, dico, è la possibilità assoluta, uno l'atto, una la forma o anima, una la materia o corpo, una la cosa, uno lo ente, uno il massimo ed ottimo; il quale non deve posser essere compreso; e però infinibile e interminabile, e per tanto infinito e interminato, e per conseguenza inmobile (CUP: 318$) .49$

\section{Conclusión}

En resumen, nuestro hipotético Plotino resulta no ser tan hipotético después de todo. De alguna manera estaba vivo, incluso como un interlocutor principal oculto en complejas conversaciones con muchos pensadores medievales, pero especialmente con el pensamiento de Nicolás de Cusa. Lo que sucedió en el Renacimiento no fue solo una recuperación de la antigüedad, sino también una profunda reorientación hacia el futuro, al pensar en las implicaciones ocultas del pensamiento antiguo tardío ejemplificado en Plotino y su herencia en todas partes. Si finalmente ponemos juntos a Plotino y Nicolás, lado a lado, después de 1492, obtenemos desafortunadamente el material combustible que conduce, en parte, a la muerte de Giordano Bruno y que pone a Galileo a prueba, pero también ofrecemos la posibilidad de que Copérnico, Kepler y Newton prosperen, incluso si necesitan vivir en un universo finito, lo cual parece que los seres humanos necesitan inevitablemente, a pesar de Anaximandro, Lucrecio, Nicolás de Cusa, Giordano Bruno. En cualquier caso, Ficino definió el futuro para muchos pensadores posteriores, aunque -a pesar de la influencia de Plotino en tantas figuras de filosofía, teología, literatura, arte, desde Leibniz, Spinoza, Hegel, Schelling hasta Thomas Taylor, More, Cudworth, Coleridge, Wordsworth, Emerson,

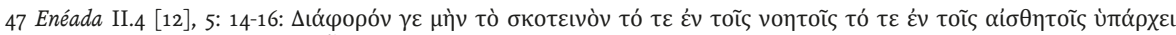

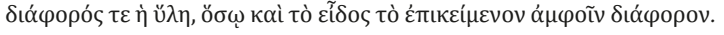

48 Proclo, ET 232, ad props. 58 y 59. Bruno llega a Plotino por medio de Ibn Gabirol (Avicebron), en cuyo pensamiento, la materia y la forma convergen (Pessin, 2013), y concluye (CPU: 299): "se la materia [...] non è corpo e precede, secondo la sua natura, l'essere corporale, che dunque la può fare tanto aliena da le sustanze dette incorporee?".

49 Compárese con Nicolás de Cusa, De visione Dei h VI.63: “Tu, enim, qui occurris mihi quasi prima materia formabilis, quia recipis formam cuislibet te intuentis, tunc me elevas". 
Dickinson- el "peligro" de Plotino se ha mantenido ubicuo desde 1492 hasta el presente. A pesar del resurgimiento actual y la respetabilidad de Plotino gracias a la editio maior y la editio minor de las Enéadas de Paul Henry y Hans-Rudolph Schwyzer, todavía se mantiene al margen de las cosas. La mayoría de las personas, incluida la gran mayoría de nuestros estudiantes, nunca han oído hablar de él. Muchos estudiosos del cristianismo, el islamismo, el judaísmo y otras religiones orientales parecen sentirse avergonzados por la necesidad de mencionar a Plotino o ignorarlo por completo. La traducción de las Enéadas de Stephen MacKenna podría ahora ser eclipsada por las de A. H. Armstrong y otros, pero su poderosa evocación de su experiencia de lectura de Plotino sigue siendo relevante para cualquier edad, resuena fuertemente con la de Ficino, y explica en gran medida la fascinación duradera de Plotino:

Whenever I look into Plotinus I feel always all the old trembling fevered longing: it seems to me that I must be born for him, and that somehow someday I must have nobly translated him: my heart, untravelled, still to Plotinus turns and drags at each remove a lengthening chain. It seems to me that him alone of authors I understand by inborn sight (Dodds, 1936: 114). 


\section{Dibliografía}

\section{Fuentes}

\section{Ediciones}

» Aristotle (1933). Metaphysics. Volume I: Books 1-9. Trad. Tredennick, H. Cambridge, MA: Harvard University Press. (Loeb Classical Library 271).

» Dionysius Areopagita (1857). De divinis nominibus. Ed. Migne, J.-P. París. (PG 3).

»Eckhardus (1936 ss). Deutsche Werke. Stuttgart: Kohlhammer.

» Giordano Bruno (1958). "De la Causa, Principio, et Uno". En: Dialogi italiani. Ed. Gentile, G. y Aquilecchia, G. Florencia: Sansoni.

» Nicolai de Cusa (1932 ss.). Nicolai de Cusa Opera Omnia. Eds. Hoffmann, E., Bormann, K., Klibansky, R., y der Wissenschaften, H. A. Leipzig-Hamburg: Meiner.

" Plotinus (1835). Opera omnia. Porphyrii Liber de vita Plotini cum Marsilii Ficini commentariis et eiusdem interpretatione castigata. Ed. Creuzer, F. Oxford: E. Typo. Academico.

» Plotinus (1984a). Enneads IV. 1-9. Bilingual edition. Trad. Armstrong, A. H. Cambridge, MA: Harvard University Press; London: William Heinemann LTD (Loeb Classical Library 443).

"Plotinus (1984b). Enneads V. 1-9. Bilingual edition. Trad. Armstrong, A. H. Cambridge, MA: Harvard University Press; London: William Heinemann LTD (Loeb Classical Library 444).

» Plotinus (1988a). Enneads VI. 1-5. Bilingual edition. Trad. Armstrong, A. H. Cambridge, MA: Harvard University Press; London: William Heinemann LTD (Loeb Classical Library 445).

» Plotinus (1988b). Enneads VI. 6-9. Bilingual edition. Trad. Armstrong, A. H. Cambridge, MA: Harvard University Press; London: William Heinemann LTD (Loeb Classical Library 468).

\section{Bibliografía complementaria}

" Adamson, P. (2016). A history of Philosophy without any Gaps: Philosophy in the Islamic World. Oxford: Oxford University Press.

"Adamson, P. (2017). The Arabic Plotinus: A Philosophical Study of the 'Theology of Aristotle' (Gorgias Islamic Studies). Nueva Jersey: Gorgias Press.

" Armstrong, A. H. (1967). "Plotinus". En: Idem (ed.). The Cambridge History of Later Greek and Early Medieval Philosophy. Cambridge: Cambridge University Press, 195-270.

» Bouillet, M.-N. (1857). "Préface". En: Plotin. Les Ennéades de Plotin. Trad. Idem. París: Hachette.

" Bussanich, J. (1988). The One and its Relations to Intellect in Plotinus: A Commentary on Selected Texts. Leiden: Brill. (Philosophia Antiqua 49).

» Bussanich, J. (2007). "Plotinus on the Being of the One". En: Finamore, J. \& Ber- 
chman, R. (eds.). Metaphysical Patterns in Platonism. Nueva Orleans: University Press of the South, 57-72.

" Corrigan, K. (2008). "Ousia and Hypostasis in the Trinitarian Theology of the Cappadocian Fathers: Basil and Gregory of Nyssa", Zeitschrift für Annikes Christentum $12,114-134$

»Corrigan, K. (2002). Reading Plotinus: A Practical Introduction to Neoplatonism. Indiana: Purdue University Press.

»Dillon, J. (1973). lamblichi Chalcidensis in Platonis dialogos commentariorum fragmenta. Leiden: Brill. (Philosophia Antiqua 23).

» Dodds, E. R. (1936). Journal and Letters of Stepehen MacKenna. Edited with a Memoir by E. R. Dodds. Londres: Constable and Co Ltd.

» D'Ancona, C. (2010). “The Origins of Arabic Philosophy”. En: Gerson, L. (ed.). The Cambridge History of Philosophy in Late Antiquity (v. II). Cambridge: Cambridge University Press, 869-893.

» Goulet-Cazé, M.-O. (1982). “L'édition porphyrienne des Ennéades. État de la question”. En: Brisson, L., Goulet-Cazé, M.-O., Goulet, R. \& O’Brien, D. (eds.). Porphyre. La Vie de Plotin. Travaux préliminaires et index grec complet (v. I). París: Vrin, 229327.

» Henry, P. (1935). Recherches sur la Préparation Évangélique d'Eusèbe et l'édition perdue des œuvres de Plotin publiée par Eustochius. París: Leroux (Bibliothèque de l'École des Hautes Études. Sciences religieuses 50).

» Henry, P. (1937). “Vers la reconstruction de l'enseignement oral de Plotin”, Bulletin de l'Académie Royale de Belgique, Classe des Lettres 23, 310-342.

» Henry, P. (1938). Études plotiniennes I. Les états du texte de Plotin. Bruselas: L'Édition Universelle.

» Henry, P. (1948). Études plotiniennes II. Les manuscrits des Ennéades. Bruselas: L'Édition Universelle.

» Hopkins, J. (1983). Nicholas of Cusa's. Metaphysics of Contraction. Mineápolis: The Arthur J. Banning Press.

» Karamanolis, G. (2006). Plato and Aristotle in Agreement? Platonics on Aristotle from Antiochus to Porphyry. Oxford: Oxford Scholarship Online.

» Коуге, A. (1957). From the Closed World to the Infinite Universe. Baltimore: The Johns Hopkins Press.

» Laurens, P. (2012). "Introduction”. En: Marsile Ficin. Commentaire sur le Banquet de Platon. De l'amour/Commentarium in Convivium Platonis. De amore.

» Lloyd, A. C. (1967). "The Later Neoplatonists". En: Armstrong, A. H. (ed.). The Cambridge History of Later Greek and Early Medieval Philosophy. Cambridge: Cambridge University Press, 272-329.

» Narbonne, J. M., Achard, M. y Ferroni, L. (ed. y trad.) (2012). Plotin. Euvres complètes. Introduction, Traité 1 (I 6): Sur le Beau. París: Les Belles Lettres.

» Natorp, P. (2004). Plato's Theory of Ideas. An Introduction to Idealism. Baden: Academia Verlag.

" O'Meara, D. (1992). Plotinus: An Introduction to the Enneads. Oxford: Clarendon Press.

" Pessin, S. (2013). Ibn Gabirol's Theology of Desire: Matter and Method in Jewish 
Medieval Neoplatonism. Cambridge: Cambridge University Press.

»Saffrey, H. (1996). "Florence, 1492: The Reappearance of Plotinus", Rennaisance Quaterly 49, 488-508.

» Sleeman, J. H. y Pollet, G. (1980). Lexicon Plotinianum. Leiden: Brill.

» Schwyzer, H.-R. (1941). "Die pseudoaristotelische Theologie und die Plotin-Ausgabe des Porphyrios", Museum Helveticum 90, 216-236.

»Schwyzer, H.-R. (1951). "Plotinos", Paulys Realenzyklopädie der klassischen Altertumswissenschaft 21, 471-592 [Con notas suplementarias en 1978, Paulys Realenzyklopädie, Suppl. 15, 321-323] Munich: Metzler.

" Thillet, P. (1971). “Indices porphyriens dans la théologie d'Aristote”. En: Hadot, P. y Schuhl, P.-M. (eds.). Le Néoplatonisme. París: CNRS, 293-302.

» Turner, J. D. (2001). Sethian Gnosticism and the Platonic Tradition. Quebec: Les Presses de l'Université Laval; Lovaina - París: Peeters. (Bibliothèque Copte de Nag Hammadi, Études 6).

»Versluis, A. (2017). Platonic Mysticism: Contemplative Science, Philosophy, Literature, and Art. Albany - Nueva York: SUNY Press.

»Zimmerman, F. W. (1986). "The Origins of the So-Called Theology of Aristotle". En: Kraye, J., Ryan, W. F. y Schmidt, C.-B. (eds.). Pseudo-Aristotle in the Middle Ages: The 'Theology' and Other Texts. Londres: Warburg Institute, 110-240. (WI Surveys and Texts XI). 
